\title{
Análise de Política Externa e Política Externa Brasileira: trajetória, desafios e possibilidades de um campo de estudos
}

Foreign Policy Analysis and Brazilian Foreign Policy: evolution, challenges and possibilities of an academic field

Rev. Bras. Polít. Int. 56 (1): 40-59 [2013]

\section{Introdução}

A Análise de Política Externa (APE) é hoje um campo de estudos bem consolidado dentro da grande disciplina das Relaçôes Internacionais (RI). Numerosos indicadores testemunham essa consolidação, como a existência de revistas especializadas (destacando-se a Foreign Policy Analysis) e de diversos manuais específicos sobre APE e capítulos sobre APE nos principais manuais de Relações Internacionais; a criação de grupos de trabalho ou seções sobre APE nas principais associações acadêmicas nacionais e internacionais de Ciência Polítical Relaçōes Internacionais (ABRI e ABCP no Brasil, International Studies Association nos EUA e British International Studies Association no Reino Unido); e a inclusão de disciplinas com essa denominação nas grades curriculares dos cursos de Relações Internacionais em todo o mundo.

Em princípio, a substância da APE não se diferencia da substância da disciplina mãe, Relações Internacionais/Política Internacional. Ambas abrangem, com efeito, todos aqueles fenômenos suscetíveis de serem incluídos no continuum conflito-cooperação e que ultrapassam as fronteiras nacionais. O que outorga especificidade à APE é seu foco nas ações internacionais de unidades particulares. Com efeito, a APE tem como objeto o estudo da política externa de governos específicos, considerando seus determinantes, objetivos, tomada de decisōes e ações efetivamente realizadas ${ }^{1}$.

\footnotetext{
* Professora do Departamento de Economia e Relações Internacionais da Universidade Federal de Santa Catarina (UFSC) (monica.salomon@ufsc.br).

** Professora do Instituto de Relações Internacionais da Pontifícia Universidade Católica do Rio de Janeiro (PUC-Rio) (pinheiro.leticia14@gmail.com).

1 Incluindo, dentro das ações realizadas, aquelas apenas anunciadas (tais como ameaças e blefes).
} 
Se tradicionalmente esse governo específico era um governo nacional, o legítimo responsável pela elaboração da política externa do Estado, nas últimas décadas os diversos processos de descentralização e regionalização associados à globalização têm feito com que outros níveis de governo diferentes do nacional (supranacionais ou subnacionais) desenvolvam suas próprias políticas externas, tornando-se assim objetos válidos da APE. A política externa da União Europeia tem sido analisada sob essa lente (White 2001), bem como aqueles governos subnacionais com atividade externa consistente (Soldatos 1990; McMillan 2008; Salomón 2011).

Em teoria, as ferramentas da APE poderiam ser também aplicadas ao estudo das ações internacionais de atores internacionais não governamentais, como empresas ou organizações não governamentais (ONGs). Contudo, isso só é realmente viável na medida em que essas unidades desenvolvam uma atividade externa planificada e coerente, ou seja, uma política (policy). Mesmo assim, as grandes diferenças entre atores governamentais e não governamentais, começando pela ausência de constituency destes últimos, limitam consideravelmente a utilidade da aplicação desse enfoque - originalmente concebido para analisar políticas governamentais - para a análise da ação externa de atores não estatais.

Isso não supõe, necessariamente, que a APE seja uma disciplina "estadocêntrica" no sentido de desconsiderar o papel de atores não estatais e de dinâmicas não protagonizadas pelo Estado na política internacional. Colocar o foco nos processos políticos estatais, como faz a $\mathrm{APE}$, não significa considerar que só estes são relevantes para compreender a realidade internacional. Aliás, a APE é bastante atenta à interação das unidades de decisão governamentais com uma pletora de variados atores dentro e fora das fronteiras do Estado que influenciam a formação e implementação dessa política pública.

A política externa, com efeito, é uma política pública, embora com uma especificidade que a diferencia do resto das políticas públicas: o fato de ser implementada fora das fronteiras estatais, o que pode levar a uma distância considerável entre objetivos e resultados ${ }^{2}$. Por sua condição de política pública, cabe distinguir a política externa da mera "ação externa", um conceito mais amplo que inclui todo tipo de contatos, planificados ou não, de um governo com outro ator fora de suas fronteiras. Por sua vez, entender a política externa como política pública leva a considerar seu processo de elaboração, no qual incidem, como em qualquer outra política pública, as demandas e conflitos de variados grupos domésticos.

Sendo a política externa uma dimensão das relações internacionais e uma política pública, não é surpreendente que a inserção disciplinar da APE tenha oscilado entre o campo da Política Pública e o das Relaçóes Internacionais. Como

2 Embora implementada fundamentalmente fora das fronteiras do Estado, a política externa resulta e promove arranjos institucionais-burocráticos domésticos diversos, bem como articulaçôes políticas internas de variadas dimensōes. 
relata Carlsnaes (2002, 331), ainda em meados dos anos 1970 a APE era percebida nos Estados Unidos mais como subárea do primeiro campo que do segundo.

Além dessa dupla vinculação, a APE tem uma forte relação com outras disciplinas, em particular com a Psicologia Cognitiva e a Psicologia Social (indispensáveis para abordar os processos de tomada de decisóes), a Sociologia, a Economia, o Direito e a História, mas também a Teoria dos Sistemas e a Neurociência, entre outras. Isso, é claro, também é verdade para a grande disciplina das Relações Internacionais. Contudo, é perceptível uma diferença de grau entre elas, com a APE especialmente dependente, no seu desenvolvimento, de contribuições transdisciplinares que nem sempre têm presença em outras áreas das Relaçôes Internacionais ${ }^{3}$.

Por fim - e não menos importante -, por APE não entendemos aqui tão somente o campo de estudos sobre a política externa centrado na análise de processo decisório. É verdade que essa dimensão foi a marca da constituição da subdisciplina conhecida por esse nome nos anos 1950. Nos dias de hoje, entretanto, seria equivocado atribuirmos à pesquisa sobre o impacto do processo decisório no conteúdo da política externa como o único objeto de investigação para o qual se volta a APE. Ao nosso entender, os estudos de processo decisório constituem hoje um, dentre outros, dos focos desse amplo campo de estudos, que inclui todos os aspectos (influências, contextos e práticas sociais, entre outros) que incidem em todas as fases (desde a formação da agenda até a implementação) de uma política externa.

No Brasil, a área de APE encontra-se em processo de consolidação. Seu instrumental teórico-conceitual é cada vez mais usado na pesquisa acadêmica e vários cursos de graduação e programas de pós-graduação em RI incluem a disciplina de APE no seu currículo. Diferentemente do passado, em que a política externa brasileira era vista como singular frente às demais políticas públicas e, portanto, pouco afeita a ser investigada por ferramentas que dessem conta de sua formulação no campo da política, na atualidade isso tem mudado consideravelmente.

Tendo em conta o exposto acima, este artigo tem dois objetivos. O primeiro é oferecer ao público brasileiro uma visão abrangente do campo de estudos de APE, condizente com a diversidade que, de fato, caracteriza a prática e a investigação sobre política externa. O segundo é mostrar as tendências pelas quais a APE vem se desenvolvendo no Brasil. Para tanto, dividimos o artigo em três seçôes, além desta introdução e da conclusão. $\mathrm{Na}$ primeira seção tratamos da constituição da subdisciplina de APE na década de 1950 e de como, após esse momento fundador, ela foi se desenvolvendo até os dias de hoje. $\mathrm{Na}$ segunda vinculamos

3 Enquanto tradicionais contribuiçōes teóricas das Relaçôes Internacionais, em particular algumas correntes do Institucionalismo e do Realismo, privilegiam o nível sistêmico e, dessa forma, prescindem de explicaçôes históricas, psicológicas, jurídicas, econômicas e outras, as explicaçôes baseadas em atores específicos, como a APE, não podem prescindir delas, nem de seus avanços em virtude da centralidade do agente na sua reflexão. Nesse particular, é digno de especial registro a relação da APE com a Psicologia Cognitiva/Neurociência, disciplinas que, por sua vez, registraram consideráveis avanços nos últimos anos. 
a $\mathrm{APE}$ às grandes perspectivas teóricas da grande disciplina das RI. Na terceira começamos fazendo referência aos estudos que podem ser considerados como antecedentes do desenvolvimento da APE no Brasil: as análises sobre a política externa brasileira feitas sob a lente da História, da Ciência Política e mesmo das Relações Internacionais, mas sem diálogo com as discussões mais específicas dentro da APE e sem considerar essa mesma produção de conhecimento sobre a realidade brasileira como inserida no campo disciplinar da APE; em seguida fazemos uma revisão preliminar da pesquisa sobre política externa brasileira realizada no Brasil que situa a si mesma dentro do campo da APE. Finalmente, a título de conclusão, fazemos um breve balanço sobre essas tendências da produção brasileira no campo, apontando possíveis caminhos para seu desenvolvimento futuro.

\section{A trajetória da APE como subdisciplina}

O artigo seminal de Richard Snyder, Henry W. Bruck e Burton Sapin, Decision-Making as an Approach to the Study of International Politics (1954), é considerado a pedra fundamental da APE como subdisciplina ou campo de estudos com identidade própria. A proposta de análise estava fortemente inserida dentro da Ciência Política behaviorista e influenciada, em particular, pelo modelo eastoniano de sistema político, nesse momento em pleno auge (Easton 1953). O ponto de partida era a ideia de que a política externa é, antes de tudo, um produto de decisões, e que o modo pelo qual as decisões são tomadas afeta substancialmente seu conteúdo. Ou seja, a política externa deveria ser investigada a partir do suposto de que ela se constitui essencialmente de uma série de decisóes tomadas por um ou mais indivíduos chamados decisores; que esses decisores agem de acordo com a definição que fazem da situação; e que essas decisões não surgem pura e simplesmente a partir dos estímulos externos, mas são sim processadas por um mecanismo dentro do Estado. Em contraponto ao que as análises sistêmicas de base realista defendiam, a partir dessa nova perspectiva o analista estaria em condiçóes de explicar por que Estados com posiçôes similares no sistema internacional comportavam-se de modos distintos.

A partir dessa contribuição de Snyder e de seus coautores, que impactou fortemente os estudos de política externa, em particular nos Estados Unidos, foram traçados dois caminhos distintos de desenvolvimento da subárea. Um, fortemente atrelado à Ciência Política behaviorista, procurou desenvolver uma "grande teoria" da política externa. Outro, metodologicamente mais plural e introduzindo elementos de diversas perspectivas disciplinares (teoria das organizações, geografia, psicologia social, psicologia cognitiva...), se materializou na construção de teorias mais específicas, de médio alcance, sobre uma grande variedade de fenômenos relacionados com a produção da política externa. Enquadrado na tentativa behaviorista de aproximar metodológica e epistemologicamente as ciências sociais às ciências naturais, o projeto de desenvolver uma Política Externa Comparada 
(Comparative Foreign Policy) sob a liderança intelectual de Rosenau (1966, 1974, 1980) foi sem dúvida o motor da subdisciplina por quase 20 anos. O ambicioso objetivo do projeto era chegar a uma teoria geral da política externa, capaz de explicar qualquer política externa e até de predizer atuações específicas. A maneira de fazer isso era identificar, a partir de dados extraídos de múltiplas fontes, as correlaçóes entre as características das nações e os tipos de comportamento de umas com relação às outras. $\mathrm{O}$ recente surgimento dos computadores facilitava as análises multivariáveis. Grandes projetos baseados na construção de enormes bancos de dados - como os projetos Interstate Behavior Analysis (IBA), Dimensions of Nations (DON), ou Comparative Research on the Events of Nations (CREON) (Hudson 2005, 20) - foram criados com esse objetivo. As secretarias de Estado e de Defesa dos EUA, confiantes de que os resultados contribuiriam a prever as açōes do inimigo soviético, os financiaram generosamente.

Porém, esses ambiciosos objetivos não foram atingidos. Em vez de uma teoria geral, os comparativistas tinham, depois de décadas de trabalho, apenas uma extensa lista de possíveis variáveis relevantes. $\mathrm{O}$ fracasso se deveu em parte a que, como reconheceu a figura fundamental do movimento behaviorista em ciência política, David Easton, os objetivos eram inatingíveis: o estudo das sociedades humanas exige métodos diferentes dos da física. E em parte porque os desenhos de pesquisa behavioristas eram bastante deficientes. Eles se baseavam, com efeito, na ideia "indutivista ingênua", pré-popperiana (Chalmers 1993), de que era possível proceder a generalizaçóes a partir da simples observação dos dados, sem uma teoria prévia a partir da qual se identificassem as conexōes relevantes ${ }^{4}$.

A falta de resultados dos comparativistas e as fortes críticas resultantes reforçaram o caminho que já vinha sendo trilhado por outros estudiosos. Assim, descartando o ambicioso objetivo inicial de construir uma teoria geral da política externa, os esforços passaram a estar focados na elaboração de teorias "de médio alcance" sobre fenômenos muito mais restritos, complementares ou não entre eles.

A título de exemplo, podemos citar o clássico trabalho de Graham Allison sobre a crise dos mísseis de Cuba (Allison 1971), origem do enfoque da "política burocrática”, muito fértil até os dias de hoje (Hilsman 1987; Kozak e Keagle 1988; Kaarbo 1998). Da mesma forma, as abordagens sociocognitivas, apoiadas em teorias dos campos disciplinares da Psicologia Social e da Psicologia Cognitiva, buscariam no estudo das crenças, percepções e imagens, entender como a dinâmica de funcionamento de um pequeno grupo (Janis 1972) ou os erros de processamento de informaçōes pelos indivíduos (Jervis 1976; Jervis, Lebow e Stein 1985; Glad 1989; George 1994) impactam sobre as decisões de política externa.

Nas últimas décadas, desde que o projeto de Política Externa Comparada foi rejeitado por seu próprio idealizador (Rosenau 1989), esse foco nos atores

4 É claro que essa é uma generalização aplicável só parcialmente a muitos dos autores comprometidos com o projeto da Comparative Foreign Policy. Em particular, não faz justiça à sutileza da Pré-teoria de Política Externa proposta por Rosenau (1966), ainda nos dias de hoje influente no desenvolvimento da área. 
específicos - líderes, pequenos grupos, organizações burocráticas mais amplas, grupos de interesse, etc. - se tornou o principal signo de identidade da subárea. Ao mesmo tempo, como veremos na próxima seção, o interesse pelos fatores domésticos nos enfoques mais gerais das Relações Internacionais foi aumentando, o que fomentou uma maior conexão entre a $\mathrm{APE}$ e a grande área de Relaçóes Internacionais.

\section{APE e as matrizes teóricas das Relações Internacionais}

\section{Contribuições liberais}

O legado liberal constitui-se, ao nosso modo de ver, na base de sustentação da subdisciplina da APE. A razão disso é a própria resposta que o liberalismo oferece às grandes questóes das Relações Internacionais: o conflito recorrente entre Estados é evitável, a cooperação é possível, e o indivíduo, agindo por meio de instituições, é o principal agente de mudança na política internacional. Uma das principais inovaçōes da nascente subdisciplina da APE nos anos 1950 foi a de abrir a caixa preta do Estado e passar a considerar a importância dos fatores domésticos na formação de políticas externas (sem que isso significasse ignorar os fatores sistêmicos); a influência das correntes liberais na APE é evidente.

A resposta liberal é oposta à realista, focada na estrutura anárquica do sistema internacional e seus efeitos, isto é, no caráter recorrente do conflito internacional. $\mathrm{Na}$ explicação realista da política internacional, as variáveis internas têm pouco peso em comparação com as variáveis sistêmicas. Nas explicaçóes liberais, pelo contrário, as variáveis internas carregam quase todo o peso da explicação.

Isso pode ser ilustrado com as contribuições dos liberais-internacionalistas na primeira metade do século 20, todas elas visando a explicar fenômenos como o imperialismo (Hobson 1902), a irracionalidade da guerra entre potências industrializadas (Angell 1913), ou o papel pacificador das organizaçóes internacionais (Zimmern 1936; Mitrany 1943) fundamentalmente por meio de variáveis internas. Posteriormente, teorias de cunho liberal como o neofuncionalismo (Haas 1958), o transnacionalismo (Deutsch 1957) ou o modelo da interdependência complexa (Keohane e Nye 1977) continuaram colocando os fatores internos no centro das explicações. A partir dos anos 1990, os defensores da "tese da paz democrática" defenderam a ideia de que um fator doméstico (tipo de regime político) é fundamental para explicar a conduta belicosa ou pacífica dos Estados, e até tentaram elevar essa tese ao status de "lei das relaçōes internacionais" (Levy 1989).

Mais recentemente, Andrew Moravcsik $(1997,2008)$ tentou redefinir a teoria liberal de maneira a incluir as principais variáveis com as quais as diferentes correntes liberais tentaram explicar a política externa/internacional: ideacionais (efeitos das ideologias ou identidades culturais na política externa); institucionais (efeitos dos tipos de instituiçõos de representação); e econômico-comerciais (efeitos dos tipos 
de políticas econômicas). O Novo Liberalismo de Moravcsik é uma tentativa de formular uma teoria geral das Relações Internacionais, dando precedência às variáveis internas sem desconsiderar, porém, o impacto das variáveis sistêmicas (Moravcsick 2008, 249). Mas existem outras propostas muito mais delimitadas também passíveis de serem inseridas dentro do paradigma liberal, como as de Putnam (1988), Milner (1997) ou Martin (2000).

\section{Contribuições realistas}

Embora, em grande medida, a APE tenha sido construída em oposição aos pressupostos realistas, isso não significa que a contribuição realista para a compreensão da política externa possa ser ignorada. De fato, excluindo o neorrealismo de Waltz, as diferentes versóes do realismo se ocuparam e continuam se ocupando da política externa.

Cabe salientar que Hans Morgenthau, sem dúvida a figura mais representativa do realismo clássico, tratou tanto das escolhas políticas do governante e outros tomadores de decisão (isto é, política externa) quanto dos fatores sistêmicos que afetam a todos os estados por igual (política internacional) (Morgenthau 1948).

Essa preocupação dos realistas com a política externa persistiu até que, com a publicação da Theory of International Politics de Kenneth Waltz, em 1979, o realismo estrutural ou neorrealismo se tornou predominante como corrente do pensamento realista (que, por sua vez, era a predominante dentro da academia de RI dos EUA). O objetivo de Waltz nessa obra era construir uma teoria da política internacional: uma teoria sobre os processos recorrentes (fundamentalmente a guerra) no sistema político internacional. Waltz não tinha a intenção de explicar políticas externas individuais. A esse respeito, ele afirmava que, dada a enorme quantidade de fatores (internos e sistêmicos) que contribuem à formação de políticas externas, é praticamente impossível elaborar teorias de política externa (Waltz 1979). Em todo caso, não era sua intenção fazer isso.

Por sua vez, sua teoria de política internacional prescinde de todos os fatores domésticos (forma de governo, de Estado, ideologia, composição de grupos de interesse) como variáveis explicativas, e mantém apenas a distribuição de poder entre as principais potencias do sistema como o principal fator condicionante (junto com a anarquia ou falta de governo centralizado) da política internacional. Fica claro então que a política internacional não é, para Waltz, a soma de políticas externas, como o era para o realismo tradicional. Tampouco aceitou Waltz a ideia apontada por autores como Elman (1996) de que mesmo sendo outra sua intenção, era sim possível inferir dos pressupostos da sua teoria de política internacional (por exemplo, o maior peso relativo dos fatores externos do que os internos) alguns elementos que permitiriam construir uma teoria neorrealista da política externa.

$\mathrm{Na}$ mesma linha de Elman, os autores da corrente do realismo neoclássico surgida nos últimos anos da década de 1990 (Schweller 1998; Wohlfort 1993; 
Zakaria 1998) declararam sua intenção explícita de construir uma teoria realista da política externa. Segundo eles, o neorrealismo e o realismo neoclássico são complementares: o primeiro trata da política internacional e o segundo, da política externa. $\mathrm{O}$ realismo neoclássico continua sendo realista porque a variável independente com a qual a política externa é explicada é a preocupação dos Estados pela posição relativa que ocupam na distribuição de poder internacional, argumento tipicamente realista. Mas não deixa de ser uma teoria de política externa porque não busca explicar questôes de política internacional (como condições para a cooperação internacional ou causas de guerra) senão a atuação de Estados individuais. Nas palavras de autores dessa corrente, o que se procura explicar é "como, e sob que condições, as características dos Estados afetam a avaliação que os lideres fazem das ameaças e oportunidades internacionais e das políticas externas diplomáticas, militares e econômicas selecionadas pelos Estados" (Lobell, Ripsman e Taliaferro 2009, tradução nossa). Ao mesmo tempo, o realismo neoclássico (re)introduz de maneira sistemática os fatores domésticos em suas explicações de política externa: recursos, capacidade de mobilização, influência dos atores sociais domésticos e grupos de interesse, nível de coesão das elites, etc. Esses fatores não são considerados os determinantes principais das políticas externas, mas sim variáveis intervenientes, presentes em modelos que dão prioridade explicativa aos fatores sistêmicos.

\section{Contribuições construtivistas}

Embora o Construtivismo tenha sido concebido (pelo menos na vertente idealizada por Alexander Wendt) como complementar ao liberalismo (Wendt 1992), seria um erro supor que ele é, como aquele, fundamentalmente uma teoria de política externa. Para começar, o Construtivismo não é, estritamente, uma teoria da política internacional/relações internacionais senão uma teoria social mais ampla que pode ser aplicada ao estudo da política internacional. Essa teoria social postula a importância do componente ideacional nas relações sociais em geral. Isto é, o papel das ideias é, para os construtivistas, tão determinante na vida social quanto os fatores materiais.

Além disso, o foco das análises construtivistas não são os Estados individuais, e sim as próprias ideias (normas, identidades, interesses) e a maneira como estas surgem, se propagam e se modificam. Os diversos atores, estatais ou não estatais, interessam aos construtivistas na medida em que participam desses processos de criação e difusão de normas.

Isso não significa que não existam conexões e influências mútuas entre o Construtivismo e a APE. Uma primeira conexão que podemos detectar é a influência dos enfoques sociocognitivos presentes na APE na constituição da corrente Construtivista em relações internacionais, influência reconhecida por vários autores (Finnemore e Sikkink 2001; Wendt 1992). Esses enfoques, com elementos provenientes da Sociologia, da Psicologia Social e da Psicologia Cognitiva, 
tinham sido deixados de lado pelas correntes dominantes em RI nos EUA, mas nunca deixaram de estar presentes na APE. Além disso, a APE e o Construtivismo guardam outra importante convergência, para além das suas respectivas ênfases na cognição, qual seja a importância que ambos atribuem à ação dos agentes na política internacional.

É possível que, na atualidade, o Construtivismo seja mais influente na APE que vice-versa, e que a rica pesquisa construtivista sobre formação de interesses (Wendt 1992, 1999), normas internacionais (Finnemore e Sikkink 1998), redes de ativismo transnacional (Keck e Sikkink 1998) ou interação de estruturas e agentes (Wendt 1999), entre outros temas, ao ser aplicada à análise das políticas externas individuais, esteja reforçando essa dimensão cognitiva que já existia na APE.

Por outra parte, embora a APE seja, como vimos, compatível tanto com explicações realistas, que dão mais peso aos fatores sistêmicos na explicação de políticas externas, quanto com explicações liberais, que postulam a preponderância dos fatores domésticos, é importante salientar que boa parte dos autores que trabalham com a APE permanecem neutros a esse respeito, deixando que a pesquisa empírica decida, para cada caso específico, que tipo de fatores teve peso maior. Isso é semelhante à posição construtivista, que, a priori, não concede um peso maior nas explicações dos fenômenos internacionais nem às estruturas nem aos agentes. Assim, de maneira semelhante aos muitos autores que, em vez de se identificarem como "liberais" ou "realistas", se identificam prioritariamente como "analistas de política externa", os construtivistas também se opõem ao determinismo das teorias tradicionais das RI. Ao nosso modo de ver, essa é uma coincidência muito salutar.

\section{Constituição e desenvolvimento do campo de estudos da APE no Brasil}

Nesta seção trataremos de dois momentos cronologicamente consecutivos do campo de estudos da APE no País. O primeiro relativo à sua formação, quando as análises sobre a política externa brasileira eram realizadas sem diálogo com as discussões mais específicas dentro da APE. O segundo momento, que nos é contemporâneo, apresenta uma visão panorâmica das tendências da pesquisa sobre política externa brasileira realizada no Brasil, agora sim inserida no campo da APE.

Se no mundo anglo-saxão o desenvolvimento da disciplina de Relações Internacionais e da subárea de Análise de Política Externa datam, respectivamente, do início e de meados do século 20, o impacto de ambas no Brasil, assim como em outros países da América Latina (Tickner 2002), foi bem posterior, começando só em meados da década de 1970 . Até então a reflexão sobre a política externa e as relaçôes internacionais encontrava-se concentrada em outros campos disciplinares e nos círculos de diplomatas, ou, como já desenvolvido em outra oportunidade, nos escritos de intelectuais enquanto diplomatas primeiramente, depois acrescidos das contribuiçôes dos diplomatas enquanto intelectuais (Pinheiro e Milani 2012). 
O tema era explorado, portanto, em grande parte no campo do Direito Internacional, do Jornalismo especializado e da História Diplomática. Evidentemente, cada um desses campos imprimia aos escritos a marca característica da natureza da sua própria narrativa: formalista e fracamente politizada no caso dos estudos inseridos no Direito Internacional Público; datada e com forte conteúdo imediatista, no caso das contribuiçôes de natureza mais jornalística; e de fortíssimo viés oficialista no caso dos estudos no campo da História Diplomática, na medida em que, nesse caso, era notória a superposição entre a atividade de pesquisa e a prática dessa mesma diplomacia (Santos 2005, 24).

O processo de institucionalização das Ciências Sociais no Brasil e o fortalecimento e expansão da universidade por meio do estabelecimento de cursos de pós-graduação nas diversas áreas de conhecimento a partir da década de 1970 viria favorecer a formação de uma comunidade acadêmica que, aos poucos, iria buscar autorização para tratar de temas de política externa e relações internacionais, juntamente com aqueles que já vinham oferecendo sua contribuição (Pinheiro e Milani 2012). Formava-se assim a área de Relações Internacionais no País.

Por outro lado, a partir dos anos 1970, o crescente multipolarismo econômico e político internacional - coexistente com a bipolaridade estratégica - abriria oportunidades para um comportamento mais flexível e proativo dos países periféricos em geral e dos latino-americanos em particular (até então mais reativos que proativos na política internacional), enriquecendo suas agendas de política externa e dando uma motivação tanto política como acadêmica ao estudo da política externa.

Este contexto levou a que acadêmicos brasileiros buscassem refletir sobre o rol de oportunidades internacionais do País no período a partir das ferramentas analíticas das Relações Internacionais. No seu conjunto, essa produção refletia em grande parte a preocupação dos formuladores da política externa brasileira de então acerca do "marco de autonomia possível da política externa, a partir do declínio da hegemonia norte-americana e das mudanças na política externa do país a partir de 1974" (Herz 2002, 18). Dentre outros trabalhos desenvolvidos nessa chave podemos citar os de Martins (1975), Lima (1986) e Camargo (1988). Mas, além dessa preocupação de ordem acadêmica e normativa sobre o período que lhes era contemporâneo, os estudiosos lançaram-se à investigação a respeito de períodos pretéritos em que as restrições sistêmicas, embora mais rígidas que as contemporâneas, não teriam impedido um comportamento mais autônomo por parte do Brasil (Hirst 1982; Moura 1980, dentre outros). Desenvolvia-se assim o campo de estudos sobre a Política Externa Brasileira, agora sob a égide da Analise de Política Externa. De fato, como bem notado por Lima, "no seu início, a área de Relaçôes Internacionais [no Brasil] se confundia com a Análise de Política Externa e ambas eram identificadas como um campo disciplinar próprio, distinto das demais disciplinas que também iniciavam seu processo de institucionalização" (Lima, no prelo). 
Além disso, o fortalecimento da produção intelectual das comunidades acadêmicas stricto sensu (em acréscimo à produção intelectual de diplomatas, inicialmente muito influente) trouxe ângulos de visão bem mais receptivos à hipótese da existência de dissenso e mesmo de conflito interno sobre os rumos da política externa brasileira, interpretação em geral ausente da produção de autoria dos diplomatas em vista de sua incompatibilidade com o quadro cognitivo desses representantes dos interesses nacionais.

O fato é que, nos dias de hoje, em decorrência da expansão e da institucionalização de cursos de graduação e pós-graduação em Relações Internacionais no País, assim como da formação de alguns profissionais em universidades estrangeiras com larga tradição na área, a produção da comunidade de estudiosos no Brasil no campo de estudos de APE é não apenas maior, mas sem sombra de dúvida feita a partir de um profícuo diálogo com a produção teórica e analítica de APE no mundo.

É de se notar que, embora a área de RI seja hoje muito maior em quantidade e em diversidade temática e teórica do que na sua formação original, isso não levou a uma redução do campo específico da APE nos estudos sobre política externa brasileira. Isso é visível tanto nas dissertações de mestrado e teses de doutorado sobre o tema como também na expressiva quantidade de trabalhos sobre a política externa brasileira apresentados nos encontros regulares das associações científicas nacionais e internacionais 5 . Da mesma forma, os periódicos nacionais especializados têm sido veículos privilegiados de divulgação de pesquisas na área ${ }^{6}$.

A liberalização do regime político brasileiro nos anos 1980 e a diversificação da pauta de interesses do País em decorrência do fim da Guerra Fria e da intensificação da globalização também são fatores que contribuíram fortemente a incrementar o interesse pelas ferramentas da APE para pensar a política externa brasileira, já que o aumento da participação de atores sociais nos debates e no processo de formulação da política externa brasileira, bem como o acesso mais democrático às informações sobre a política externa, estimularam os pesquisadores a investigar o papel desses novos atores na política externa.

Por fim, a crescente visibilidade do Brasil na comunidade internacional aumentou o interesse por parte de pesquisadores sobre a política externa do País, além de expandir ainda mais o leque de temas a constituir a agenda da política externa brasileira. Desse contexto resulta um retrato bastante promissor da área, cujas tendências resumiremos a seguir.

No corte mais convencional da APE, ou seja, aquele voltado para o exame das unidades de decisão e do processo decisório stricto sensu, os estudos sobre a

5 Em pesquisa realizada há quatro anos, constatou-se que entre 1998 e 2006 o tema de Política Externa Brasileira foi o mais presente nas dissertações e teses defendidas nos principais Programas de Pós-Graduação em Relações Internacionais, conforme registrado pelo sistema da Coordenação de Aperfeiçoamento de Pessoal de Nível Superior (Capes); e que, entre 2000 e 2006, esse eixo de investigação ocupou o primeiro e segundo lugares dentre os trabalhos apresentados nas principais associaçōes científicas brasileiras (Pinheiro 2008).

6 O mesmo não se pode dizer sobre os periódicos internacionais - particularmente os de língua inglesa -, que ainda registram baixíssima presença de autores da comunidade brasileira de estudiosos de política externa. 
política externa brasileira tem sido relativamente tímidos. De fato, para além de pesquisas que buscaram lançar luz sobre o funcionamento da arena decisória da política externa brasileira durante o período militar autoritário que, ao contrário do que afirmavam as teses então vigentes, demonstraram a grande complexidade do período (Gonçalves 1993; Pinheiro 2000), só recentemente surgiram novas perspectivas de trabalho nessa linha. Concorreu para esse renovado interesse a respeito das unidades decisórias a própria mudança ocorrida no cenário doméstico e internacional que potencializou a presença de novas unidades no processo de decisão. Assim, a presença dos governos subnacionais - municípios e estados - na construção de parcerias internacionais para o País tornou-se objeto de investigação de alguns pesquisadores (Vigevani 2004; Salomón 2011), assim como a ação externa dos chamados ministérios domésticos e outras agências federais, que vêm alterando a arquitetura da arena decisória, trouxe para o debate a literatura sobre minorias burocráticas (Kaarbo 1998), como fizeram Macedo (2008) e outros.

Deve-se registrar, igualmente como um primeiro passo na direção de reflexões mais analíticas, as pesquisas que buscam mapear esse novo arranjo institucional (Rivarola Puntigliano 2008; França e Sanchez Badin 2010; Figueira 2011; Pinheiro 2009). Apesar de a discussão sobre as conseqüências desta nova configuração (Pinheiro e Milani 2012) ser ainda incipiente, essa preocupação que encontra respaldo na literatura sobre Administração Pública, Políticas Públicas e Sociologia das Instituiçôes certamente fornecerá insumos essenciais para futuras pesquisas de fôlego mais analítico. Ainda no campo de processo decisório, a análise cognitiva tem sido uma ferramenta utilizada com bastante sucesso. Arbilla (2000), por exemplo, demonstrou como os arranjos institucionais domésticos foram responsáveis por mudanças conceituais adaptativas e graduais e que a reformulação do quadro conceitual da diplomacia brasileira constituiu um complexo processo político no qual estava em jogo a própria implementação das mudanças nas respectivas agendas externas. Já Silva (1995) propôs uma análise a respeito da influência das ideias sobre a formulação da política externa brasileira focalizada na atuação do País na Liga das Nações e nas Nações Unidas utilizando uma série de enfoques que dão ênfase aos fatores ideacionais (Goldstein e Keohane 1993; Vetzberger 1990; Yee 1996).

Outros, embora claramente inseridos nesse mesmo campo, afirmam se inserir no campo do Construtivismo, o que só ajuda a confirmar as tangencias entre este e a análise cognitiva, conforme referido acima. Esse é o caso, por exemplo, de Saraiva e Briceño Ruiz (2009), que analisaram as percepções de atores políticos domésticos no interior dos maiores países membros do Mercosul a respeito do processo de integração, assim como as ideias presentes na esfera pública de apoio ou de rejeição ao bloco.

No campo das contribuições realistas, vale registrar a presença de um trabalho (Alves 2002) que irá buscar em Waltz as explicações para o comportamento do Brasil durante a 2a Guerra Mundial. O mesmo Alves (2007) iria, anos mais tarde, retomar o realismo como perspectiva teórica para analisar comparativamente a 
posição do Brasil frente à 2a Guerra Mundial e a guerra da Coreia. Dessa feita, porém, o autor busca na vertente neoclássica do realismo a explicação para o comportamento do Brasil, entendendo que variáveis intervenientes domésticas tiveram peso explicativo para os dois casos.

Já com relação ao viés liberal, os exemplos abundam. O modelo do Jogo de Dois Níveis tem despertado particular interesse dos estudiosos que examinam a política externa brasileira nos fóruns comerciais internacionais. Curiosamente, porém, esta que tem sido uma das linhas de investigação mais presentes no campo é também a que revela mais lacunas na utilização do modelo, talvez pela sua exigência intrínseca de ter que incorporar um considerável volume de dados empíricos. Ainda assim podemos citar como um exemplo, dentre vários outros, de sua utilização o trabalho de Oliveira (2003) sobre o contencioso do açúcar entre Brasil e Argentina no Mercosul.

O conceito de estruturas domésticas desenvolvido por Risse-Kapen (1995) também é um instrumento de investigação que vem sendo utilizado. Apoiado nele e com louvável atenção à pesquisa empírica, Carvalho (2003) trata do papel de grupos de interesse na formação da posição oficial brasileira para a III Conferência Ministerial da Organização Mundial do Comércio (OMC), em Seattle, em 1999. Da mesma forma, alguns pesquisadores têm lançado mão da contribuição de Martin (2000) e de Milner (1997) para analisar a relação entre Poder Executivo e Poder Legislativo na política externa brasileira. O trabalho de Alexandre (2006), por exemplo, apresenta resultados muito interessantes ao demonstrar a validade da hipótese de delegação sugerida por Martin no papel do Congresso Brasileiro na política externa. Em linha semelhante, a pesquisa de Castro Neves (2003) examina a relação entre os poderes Executivo e Legislativo na formulação da política externa com relação aos acordos do Mercosul e da Área de Livre Comércio das Américas (Alca), apontando para o papel efetivo do Legislativo na defesa dos seus interesses, apesar da centralidade do poder Executivo no processo decisório em matéria de política externa. Vale destacar igualmente que o papel do Poder Legislativo vem sendo também avaliado a partir da investigação sobre como se comportam os grupos de interesse brasileiros na política comercial por meio da sua ação no Congresso Nacional (Oliveira e Onuki 2008).

Já o Construtivismo também tem atraído diversos pesquisadores interessados em avaliar a co-constituição agente e estrutura na política externa brasileira e não apenas o papel das ideias no comportamento dos formuladores de decisão, mas também de onde vêm essas ideias, crenças e valores e, mais, o que ocorre quando essas mesmas ideias são socialmente compartilhadas e permanecem válidas por um tempo mais longo. A titulo de exemplo, vale citar o trabalho de Mello e Souza (2007) a partir do modelo de Keck e Sikkink (1998) sobre a influência das redes de advocacia transnacional no sucesso brasileiro por ocasião da disputa comercial com os EUA em torno dos direitos de propriedade intelectual relativos a patentes farmacêuticas de remédios contra a Aids. 
Por fim, há também a opção por dialogar com outras disciplinas, expandindo assim as possibilidades de compreensão sobre a política externa brasileira. Esse é o caso, por exemplo, de Vedoveli (2010), que, por meio do estudo dos conceitos empregados por Rio Branco, Joaquim Nabuco e Oliveira Lima, associou a discussão sobre construção de identidade elaborada por Kratochwil (2006) às ferramentas da História, em particular da História dos Conceitos (Koselleck 1992).

\section{Considerações finais}

Nossa visão positiva sobre o presente e o futuro desse campo de estudos no Brasil não impede que apontemos para algumas lacunas que precisam ser prontamente preenchidas, considerando os trabalhos citados como exemplos das linhas epistemológicas e metodológicas mais contempladas atualmente no País. A primeira delas refere-se à discussão sobre a influência da opinião pública na formulação e conteúdo da política externa brasileira, carência já registrada por Faria (2008). Nesse sentido, de bom grado recebemos a pesquisa realizada por Franco publicada em 2009, assim como os surveys realizados com a chamada comunidade de política externa brasileira, conforme denominação de Souza, em duas diferentes oportunidades (2001, 2008). Da mesma forma, gostaríamos de registrar o survey, ainda em andamento, sob coordenação de Maria Hermínia Tavares de Almeida no âmbito do projeto do Centro de Investigación y Docencia Económicas (Cide/ USP), intitulado O Brasil e o Mundo, cujos primeiros resultados já estão disponíveis ao público ${ }^{7}$. Não podemos deixar de sublinhar, entretanto, que o acesso aos dados não dispensa os pesquisadores de enfrentar a difícil tarefa de conceituar opinião pública, assim como de imputar causalidades.

Outra lacuna, a nosso ver mais surpreendente, refere-se aos estudos centrados no líder. Essa ausência nos chama atenção não apenas pela natureza do presidencialismo imperial brasileiro (Lima 2000), o que por si só já seria razão suficiente para avaliar as características particulares do mandatário na política externa; mas, igualmente - e ainda que de modo fortuito -, pelas características particulares dos nossos líderes mais recentes, cujos carisma, centralismo e ascendência apenas reforçam a importância dessa linha de investigação.

Por fim, cabe reafirmar que este artigo não pretendeu mais do que compartilhar com nossos leitores a nossa visão sobre o campo de estudos de APE e seu desenvolvimento no Brasil. Resta-nos apenas registrar que em nenhum momento pretendemos realizar um levantamento exaustivo da produção brasileira a respeito. Nosso objetivo foi tão somente indicar que perspectivas analíticas foram utilizadas - algumas mais intensamente, outras menos -, que diálogos interdisciplinares foram e têm sido realizados e que caminhos ainda podem e devem ser trilhados.

7 Disponível em <http://mexicoyelmundo.cide.edu/2010/ReporteLasAmericasyelMundo2010.pdf>. 
No entanto, para além dessa avaliação panorâmica, talvez valha reiterar um único aspecto. De fato, não só devido à sua relevância epistemológica, como também por seu caráter de estímulo para os que já se dedicam a pesquisas nesse campo de estudos e para os que ainda poderão vir, consideramos importante sublinhar aquela que é, a nosso modo de ver, a marca desse campo de estudos: sua pluralidade e abertura a novas perspectivas. Esse traço não apenas vem permitindo contemplar a própria reconfiguração pela qual passa a própria política externa nos dias atuais, como nos capacita como cidadãos a atuar sobre ela.

\section{Referências bibliográficas}

ALEXANDRE, Cristina V. M. O Congresso Brasileiro e a Politica Externa (1985-2005), Dissertação de Mestrado, PUC-Rio, 2006.

ALLISON, Graham T. Essence of Decision - Explaining the Cuban Missile Crisis, Boston, Little Brown \& Co., 1971, pp. 10-66.

ALVES, Vágner Camilo. Brasil e a Segunda Guerra Mundial. Rio de Janeiro, Loyola, 2002.

ALVES, Vágner Camilo. Da Itália a Coréia - decisões sobre ir ou não à Guerra. Belo Horizonte, Ed. UFMG, 2007.

ANGELL, Norman. The Great Illusion: A Study of the Relation of Military Power in Nations to their Economic and Social Advantage. Londres, W. Heinemann, 1913.

ALMOND, Gabriel A. "Political Science: The History of the Discipline", in Robert Goodin e Hans-Dieter Klingemenn eds., A New Handbook of Political Science. Oxford, Oxford University Press, pp. 50-96.

ARBILLA, José María. A diplomacia das idéias: a politica da renovação conceitual da politica externa na Argentina e no Brasil (1989-1994). Contexto Internacional, vol. 2, no. 2, julhodezembro 2000, pp. 337-385.

CAMARGO, S. de. Autoritarismo e Democracia na Argentina e Brasil. São Paulo, Ed. Convívio, 1988.

CARLSNAES, Walter. "Foreign Policy" in: Carlsnaes, Walter, Risse, Thomas e Beth Simmons (eds.), Handbook of International Relations, London: Sage, 2002, pp. 331-349.

CARVALHO, Maria Izabel V. de "Estruturas Domésticas e Grupos de Interesse: A Formação da Posição Brasileira para Seattle”, in Contexto Internacional, vol. 25, n. 2, 2003, pp. 363-401.

CASTRO NEVES, João Augusto de. "O Papel do Legislativo nas Negociações do Mercosul e da ALCA", in Contexto Internacional, vol. 25, no. 1, 2003, pp. 103-38.

CHALMERS, Alan O que é Ciência afinal? São Paulo: Brasiliense, 1993.

DE CERTEAU, M. A escrita da História. Rio de Janeiro: Forense-Universitária, 1982.

DEUTSCH, Karl, (e.a.). Political Community and the North Atlantic Area. Princeton, Princeton University Press, 1957.

DOYLE, Michael W. "Liberalism and Foreign Policy" in Smith, Steven, Hadfield, Amelia e Dunne, Tim (eds.) Foreign Policy. Theories, Actors, Cases. Oxford, Oxford University Press, 2008, pp. 49-70. 
EASTON, David. THE POLITICAL SYSTEM New York, Alfred A. Knopf, Inc.; 1953.

ELMAN, Colin "Horses for Courses: Why Not Neorealist Theories of Foreign Policy?", Security Studies, vol. 6, no 1, 1996, pp. 7-53.

FARIA, C. A. P. de. "Opinião Pública e Política Externa: Insulamento, Politização e Reforma na Produção da Política Exterior do Brasil”, Revista Brasileira de Política Internacional, vol. 51, no. 2, pp. 80-97, 2008.

FIGUEIRA, Ariane. Horizontalização decisória nas arenas políticas setoriais. Revista de Economia ↔ Relaçôes Internacionais. Vol. 9 / num. 18 / janeiro 2011, pp. 19-34.

FINNEMORE, Martha e SIKKINK, Katherine, "International Norm Dynamics and Political Change”, International Organization, vol. 52, no. 4, 1998, pp. 887-917.

FINNEMORE, Martha e SIKKINK, Katherine, "Taking Stock: The Constructivist Research Program in International Relations and Comparative Politics", Annual Reviews in Political Science, vol. 4, 2001, pp. 391-416.

FRANCO, Geisa. C. Opinião Pública e Política Externa na Abertura Democrática Brasileira (1979-1985). 1. ed. Curitiba: Juruá, 2009. v. 1. 248 p.

FRANÇA, Cássio L. de \& SANCHEZ BADIN, Michelle Ratton "A Inserção Internacional do Poder Executivo Nacional Brasileiro". Analises e Propostas, Friedrich Ebert Stiftung, 2010.

GEORGE, A. L. “The Two Cultures of Academia and Policy-Making: Bridging the Gap”. Political Psychology 15:143-171, 1994.

GERNER, Deborah J., “The Evolution of the Study of Foreign Policy”, in Neack, Laura, Hey, Jeanne A. K. e Haney, Patrick J. (eds.) Foreign Policy Analysis - Continuity and Change in its Second Generation. Prentice Hall, Englewood Cliffs, New Jersey, 1995, pp. 17-32.

GLAD, B. "Personality, Political, and Group Process Variables in Foreign Policy DecisionMaking: Jimmy Carter's Handling of the Iranian Hostage Crisis”. International Political Science Review 10:35-61, 1989.

GOLDSTEIN, Judith e KEOHANE, Robert. Ideas and Foreign Policy. Ithaca, Cornell University Press, 1993.

GONÇALVES, Williams da Silva. Os militares na politica externa brasileira: 1964-1984. Estudos Históricos, Rio de Janeiro, v. 6. 11. 12. 1993, p. 211-246.

HAAS, Ernst B. The Uniting of Europe. Stanford, Stanford University Press, 1958.

HERZ, M. O Crescimento da Área de Relaçôes Internacionais no Brasil. Contexto Internacional, v. 24, n. 1, p. 7-40, 2002.

HILL, Christopher. The Changing Politics of Foreign Policy. Londres: Palgrave Macmillan, 2003.

HILSMAN, R. The Politics of Policy-Making in Defense and Foreign Policy: Conceptual Models and Bureaucratic Politics. Englewood Cliffs, NJ: Prentice Hall, 1987.

HIRST, M. O Processo de Alinhamento nas Relações Brasil-Estados Unidos: 1942-1945. Dissertação de Mestrado, IUPERJ, Rio de Janeiro, 1982.

HOBSON, John A. Imperialism: A Study. New York, James Pott \& Co, 1902.

HUDSON, Valerie. "Foreign Policy Analysis: Actor - Specific Theory and the Ground of International Relations", Foreign Policy Analysis, vol. 1, issue 1, 2005, pp. 1-30.

JANIS, Irving. Victims of Groupthink. Boston: Houghton Mifflin, 1972. 
JERVIS, Robert. Perception and Misperception in International Politics, Princeton, Princeton University Press, 1976.

JERVIS, R., R. N. LEBOW, AND J. G. STEIN (eds.) Psychology and Deterrence. Baltimore, MD: Johns Hopkins University Press, 1985.

KAARBO, Juliet, "Power Politics in Foreign Policy: The Influence of Bureaucratic Minorities", European Journal of International Relations, March 1998, Volume 4: 67-97.

KECK, Margareth e SIKKINK, Katherine. Activist beyond borders: advocacy networks in international politics. Cornell: Cornell University Press, 1998.

KEOHANE, Robert O. e Nye, Joseph, Power and Interdependence. World Politics in Transition: Boston, Little Brown, 1977.

KOSELLECK, R. Uma História dos conceitos: problemas teóricos e práticos. Estudos Históricos, v. 5, n. 10, p. 134-146, 1992.

KOZAK, D. C., J. e KEAGLE, M. (eds.) Bureaucratic Politics and National Security: Theory and Practice. Boulder, CO: Lynne Rienner, 1988.

KRATOCHWIL, F. History, Action and Identity: Revisiting the 'Second' Great Debate and Assessing its Importance for Social Theory. European Journal of International Relations, v. 12, n. 1, p. 5-29, 2006.

LEVY, Jack, "Domestic Politics and War", in Rotberg, R. e Rabb, Th. (eds.), The Origin and Prevention of Major Wars, Cambridge, Cambridge University Press, 1989.

LIMA, Maria Regina Soares de. The Political Economy of Brazilian Foreign Policy: Nuclear Energy, Trade and Itaipú. Tese de Doutorado, Nashville, Vanderbilt University, 1986.

LIMA, Maria Regina Soares de. "Instituiçôes Democráticas e Política Exterior". Contexto Internacional, vol. 22, no. 2, 2000.

LIMA, Maria Regina Soares de. Relaçôes Internacionais e Politicas Públicas: A Contribuição da Análise de Politica Externa. (no prelo).

LOBELL, Steven, RIPSMAN, Norrin e Jeffrey TALIAFERRO (eds.), Neoclassical Realism and the State. Cambridge, Cambridge University Press, 2009.

MACEDO, Vanessa Rodrigues de. "A Contribuição de uma Organização Social para Ciência, Tecnologia e Inovação: O Caso da RNP", in João Alberto De Negri e Luis Claudio Kubota (Editores), Políticas de Incentivo à Inovação Tecnológica, Brasília, 2008, pp. 535-580.

MARTIN, Lisa, Democratic Commitments: Legislatures and International Cooperation. Princeton: Princeton University Press, 2000.

MARTINS, C.E. "A Evolução da Política Externa Brasileira na Década de 64/74". Estudos Cebrap, no. 12, 1975.

McMILLAN, Samuel Lucas. "Subnational Foreign Policy Actors: How and Why Governos Participate in U.S. Foreign Policy”. Foreign Policy Analysis, vol. 4, no. 3, 2008, pp. 227-253.

MELLO E SOUZA, André de. Patent Rights Vs. Health Rights: Globalization and the Politics of AIDS Treatment in Brazil. In: 48th Annual Convention of the International Studies Association, 2007, Chicago. Paper Archive of the ISA Convention, 2007.

MILNER, Helen. Interests, Institutions, Information. Domestic Politics and International Relations. Princeton: Princeton University Press, 1997. 
MITRANY, David. A Working Peace System. Londres: Royal Institute of International Affairs, 1943.

MORAVCSIK, Andrew. "Taking Preferences Seriously. A Liberal Theory of International Politics”, International Organization, vol. 51, no. 4, 1997, pp. 513-553.

MORAVCSIK, Andrew, "The New Liberalism", in Snidal, D. e Reus-Smit, Ch. (eds.), The Oxford Handbook of International Relations. Oxford, Oxford University Press, 2008, pp. 234-254.

MORGENTHAU, Hans, Politics among Nations: The Struggle for Power and Peace. Chicago: University of Chicago Press, 1948.

MOURA, G. Autonomia na Dependência: A Política Externa Brasileira de 1935 a 1942. Rio de Janeiro, Nova Fronteira, 1980.

OLIVEIRA, Marcelo Fernandes de. Mercosul - atores políticos e grupos de interesses brasileiros, São Paulo, UNESP, 2003.

OLIVEIRA, Amâncio; ONUKI, Janina. Grupos de interesses e a Politica Comercial Brasileira: A Atuação na Arena Legislativa. Papéis Legislativos (n. 8, dez. 2007).

PINHEIRO, Letícia. International Relations Studies in Brazil: Epistemological and Institutional Characteristics. Comunicação apresentada em International Political Science Association Conference, Montreal; Québec, 2008.

PINHEIRO, Letícia. Autores y Actores de la política exterior brasileña. Foreign Affairs Latinoamérica. Vol. 9, n. 2, 2009, pp. 14-24.

PINHEIRO, Letícia. "Unidades de decisão e processo de formulação de política externa durante o regime militar", in José A.G. de Albuquerque (ed). Sessenta Anos de Politica Externa Brasileira, vol. 4, São Paulo, Anablume/NUPRI/USP, 2000, pp. 449-474.

PINHEIRO, Letícia; MILANI, Carlos R. S. (orgs.) (2012). Política Externa Brasileira: As Práticas da Política e a Política das Práticas. Rio de Janeiro, Editora da Fundação Getúlio Vargas.

PINHEIRO, Leticia; VEDOVELI, Paula. "Caminhos cruzados: diplomatas e acadêmicos na construção do campo de estudos de Política Externa Brasileira”, Revista Política Hoje, Vol. 21, n. 1, pp. 10-25.

PUTNAM, Robert, "Diplomacy and Domestic Politics: The Logic of Two-Level Games", International Organization, vol. 43, no. 3, 1998, pp. 427-460.

RISSE-KAPEN, Thomas. (1995), Bringing Transnational Relations Back In: Introduction., in T. Risse-Kapen (ed.), Bringing Transnational Relations Back In: Non-state Actors, Domestic Structures and International Institutions. Cambridge, Cambridge University Press, pp. 3-33.

RIVAROLA PUNTIGLIANO, Andrés 'Going Global': An Organizational Study of Brazilian Foreign Policy, Rev. Bras. Polit. Int. 51 (1): 28-52, 2008.

ROSENAU, J. N. "Pre-theories and Theories of Foreign Policy." In Farrell, R. B. (ed.), Approaches in Comparative and International Politics. Evanston: Northwestern University Press, 1966, pp. 115-169.

ROSENAU, James N. (ed.) Comparing Foreign Policies. Theories, Findings and Methods. Halsted Press, 1974.

ROSENAU, James N. The Scientific Study fo Foreign Policy. New York, Nichols Publishing Company, 1980. 
ROSENAU, James N. “The Scholar as an Adaptive System”, in: Journeys Through World Politics. Reflections of Thirty-Four Academic Travellers. Lexington, Lexington Books, 1989.

SALOMÓN, Mónica. "Paradiplomacy in the Developing World. The Case of Brazil" in Amen, Mark e.a. (ed.), Cities and Global Governance. New Sites for International Relations. Londres, Ashgate, 2011, pp. 45-68.

SALOMÓN, Mónica. La Acción de Los Gobiernos Subnacionais y el Análisis de Políticas Exteriores. Trabalho apresentado no 1º Encontro Nacional da ABRI, Brasília, 2007.

SANTOS, Norma Breda. História das Relações Internacionais no Brasil: esboço de uma avaliação sobre a área. História, São Paulo, v. 24, n. 1, p. 11-39, 2005.

SARAIVA, Miriam Gomes e BRICEÑO RUIZ, José, “Argentina, Brasil e Venezuela: as diferentes percepções sobre a construção do Mercosul". Revista. Brasileira de Política Internacional, 2009, vol. 52, n. 1, pp. 149-166.

SCHWELLER, Randall. Deadly Imbalances: Tripolarity and Hitler's Strategy of World Conques. Columbia University Press, 1998.

SEITENFUS, R. A. S. O Brasil de Getúlio Vargas e a Formação dos Blocos: 1930-1942. São Paulo, Companhia Editora Nacional, 1985.

SIKKINK, Kathryn. Ideas and Institutions - Developmentalism in Brazil and Argentina. Ithaca, Cornell University Press, 1991.

SILVA, A. M. S. O Brasil no Continente e no Mundo: atores e imagens na política externa brasileira contemporânea. Estudos Históricos, vol. 8, n. 15, p. 139-158, 1995.

SMITH, Steve. "Theories of foreign policy: an historical overview" in: Review of International Studies, vol. 12, n. 1, Jan. 1986.

SNYDER, R., BRUCK, H. W. e SAPIN, B. Decision-Making as an Approach to the Study of International Politics. Princeton: Princeton University Press, 1954.

SOLDATOS, Panayotis "An Explanatory Framework for the Study of Federated States as Foreign-policy Actors", in Federalism and International Relations. The Role of Subnational Units. edited by H. J. Michelmann and P. Soldatos. Oxford: Clarendon Press, 35-53, 1990.

SOUZA, Amaury. "Agenda Internacional do Brasil" - Centro Brasileiro de Relações Internacionais, 2001.

SOUZA, Amaury. Agenda Internacional do Brasil Revisitada: Percepções da Comunidade Brasileira de Política Externa. - Centro Brasileiro de Relações Internacionais, 2008

SOUZA, Celina. "Políticas Públicas: uma revisão da literatura", Sociologias, Porto Alegre, ano $8, n^{\circ} 16$, jul/dez 2006, p. 20-45.

SPROUT, Harold, and Margaret Sprout. Man-Milieu Relationship Hypotheses in the Context of International Politics. Princeton, N.J., 1956.

TICKNER, A. B. Los Estudios Internacionales en América Latina: ¿Subordinación intelectual o pensamiento emancipatório? Bogotá: Universidad de los Andes; Alfaomega Colombiana, 2002.

VEDOVELI, PAULA. Continuidade e Mudança na História Intelectual Diplomática Brasileira: Uma Análise da Construção da Tradição, Dissertação de Mestrado, PUC-Rio, 2010.

VERTZBERGER, Yaacov. The World in their Minds - Information Processing, Cognition and Perception in Foreign Policy Decision Making. Stanford: Stanford University Press, 1990. 
VIGEVANI, Tullo e.a. (eds.), A dimensão subnacional e as relações internacionais. São Paulo: EDUC, 2004.

WALTZ, Kenneth, Theory of International Politics, New York: McGraw Hill, 1979.

WALTZ, Kenneth, "Realist Thought and Neorealist Theory", Journal of International Affairs, 1990, pp. 21-37.

WENDT, Alexander, "Anarchy is what states makes of it: the social construction of Power politics". International Organization, 46, 1992, pp. 391-425.

WENDT, Alexander, Social theory of international politics. Cambridge: Cambridge University Press, 1999.

WOHLWORTH, William. The Elusive Balance: Power and Perceptions during the Cold War, Ithaca: Cornell University Press, 1993.

WHITE, Brian. Understanding European Foreign Policy. Londres: Palgrave, 2001.

YEE, Albert S. “The causal effects of ideas on policies”. International Organization. 50(1), 1996.

ZAKARIA, Fareed. From Wealth to Power: The Unusual Origins of America's World Role. Princeton: University Press, 1998.

ZIMMERN, Alfred. The League of Nations and the Rule of Law. Londres: McMillan, 1936.

Recebido em 23 de agosto de 2012 Aprovado em 10 de fevereiro de 2013

\section{Resumo}

No artigo é apresentada uma visão panorâmica da subdisciplina Análise de Política Externa (APE), na tentativa de refletir a diversidade que caracteriza a prática e a pesquisa nesse campo. Também mostra como a APE está se desenvolvendo no Brasil. Na primeira seção se apresenta de maneira sucinta a evolução da subdisciplina. Na segunda seção são assinalados os vínculos entre as principais aproximações teóricas das Relações Internacionais (RI) e da APE. Na terceira revisamos como os instrumentos da APE têm sido usados para analisar a Política Externa Brasileira.

Palavras chave: Análise de Política Externa; Política Externa Brasileira; processo decisório.

\section{Abstract}

The article offers a wide-ranging view of the sub-discipline of Foreign Policy Analysis (FPA), trying to reflect the diversity which characterizes the practice and the research in the field. It also shows how FPA has being developing in Brazil. In the first section a brief evolution of the sub-discipline is traced. In the second section the links between the main theoretical International Relations (IR) approaches and FPA are shown. In the third section we review the uses of FPA instruments to analyze Brazilian Foreign Policy.

Keywords: Foreign Policy Analysis; Brazilian Foreign Policy; decision-making process. 